\title{
Surfactant Adsorbed at the Oil-Water Interface and Its Elimination
}

\author{
Linfeng Yang, Leonidas Perez Estrada \\ Department of Civil and Environmental Engineering, University of Alberta, Edmonton, Canada \\ Email: linfeng@ualberta.ca
}

Received February 2015

\begin{abstract}
Surfactants are widely used in the petroleum industry as one kind of Enhanced Oil Recovery methods (EOR). The oil sands mines in Northern Alberta are the largest one in the world. Due to using sodium hydroxide in bitumen extraction process, there are a lot of surfactant molecules in the tailing water. The surfactants from oil sands industry have brought a potential threat to the environment and human health. Depending on the performance of surfactant at the interface, this work focuses on removing these harmful surfactants from the tailing water and not bringing other possible hazardous substances. Moreover, a mathematical model is built to calculate the removal efficiency of the surfactant. The time required for removing the surfactant is determined experimentally. In conclusion, most of surfactant molecules are adsorbed at the oil/water interface. The fraction of the surfactant staying at the oil/water interface is high. Most of the surfactants in tailing water can be eliminated. The time of surfactant migration can be used for setting up the update time of the oil film in the automatic instrument, which can be designed in the future.
\end{abstract}

\section{Keywords}

Surfactant, Adsorption Equilibrium, Membrane, Surface Tension, Naphthenic Acids, Oil Sands Process-Affected Water

\section{Introduction}

Surfactants are chemical molecules which widely exist in the nature. They can help to decrease the surface tension of water even if the concentration is very low. Based on their surface property, surfactant molecules can surround the oil droplets by inserting the hydrophobic groups into the oil and placing the hydrophilic groups in the water. Hence, the oil disperses in the water and forms a stable emulsion. The bitumen contains much more surfactant compounds, which leach and/or leak into the water during oil sands extraction process. Two types of surfactant molecules in oil sands process-affected water (OSPW): Carboxylic type (naphthenic acid) and Sulfonic type (sulfonic acid) were determined by a foam fractionation and acid titration technique [1] or cationic surfactant titration technique monitored by dynamic surface tension measurement [2]. Surfactants help to increase the extraction efficiency of bitumen by surrounding the droplet of bitumen and let the bitumen detach from mineral sands, they remain in the tailing water. Some oil sands tailing ponds are near rivers or groundwater sources, increasing the risk of leaking and/or leaching the naphthenic acids (NAs) from the ponds into the soil 
and water sources. The nearest river to the oil sands region is the Athabasca river where the NAs concentration can be close to $1 \mathrm{mg} / \mathrm{L} \mathrm{[3]}$. In the near-surface groundwater, the concentration of NAs can be close to $4 \mathrm{mg} / \mathrm{L}$, and it is much higher in the limestone aquifer than the former [4]. For organisms, especially human, they cause great hazards. NAs is toxic for human (lethal dosage LD50 $=11 \mathrm{~g} / \mathrm{Kg}$ body weight) [5]. They may cause a long term threaten, even cancer [6]. Chemical, such as ozone, can also leave derivatives to the water after the treatment process, which may be new pollutants. Scott et al. [7] found that NAs in oil sand tailing water was less biodegradable. The higher NAs cyclization number would lead to lower biodegradability [8]. A new process should be designed for eliminating NAs from OSPW and not leaving other pollutants.

\section{Materials and Methods}

\subsection{Materials and Reagents}

Sodium dodecyl benzene sulfonate (SDBS) and sodium laurate (SLA) will be used as standard surfactants and paraffin oil, diesel and soybean oil will be used as the oil phase materials. Sodium hydroxide will be applied for adjusting $\mathrm{pH}$ value. Filter membrane will be used to prevent the oil leaking from the adsorption oil film, such as PS, PVDF, PES, $\mathrm{ZrO}_{2}$ or cellulose hollow fiber membranes [9]. OSPW will be used as the real effluent containing surfactants and it will be compared with tailings created in the lab from oil sands ore samples.

\subsection{Custom Made Device}

Custom made device is shown in Figure 1, whose stirrer is used for accelerating diffusion, whose door is used to close the device for separating the oil film and adsorbed surfactants from the solution. The diameter of custom made device will be $8 \mathrm{~cm}$, the height will be $10 \mathrm{~cm}$, and its volume will be about $500 \mathrm{ml}$. It can be made from a canned box. Two narrow notches near the bottom will be made, one will be placed filter membrane, the other will be placed the door. The stirrer is double leaves propeller with $2 \mathrm{~cm}$ length paddle and will rotate for agitation. Surfactants will be adsorbed at the oil film and filter membrane in this device.

\subsection{Experimental Setup}

Initially a standard mixture of SDBS and SLA with molar ratio of 1: 1 will be prepared at different concentrations of 5, 25, 45, 65, 85, 105, 125, $145 \mathrm{mg} / \mathrm{L}$. Sodium hydroxide will be added to adjust $\mathrm{pH}$ to 8.5 .

The surface tension $(\sigma)$ of the mixture solution of SDBS and SLA will be measured by force tensiometer. Then the activity of surfactant solution could be calculated from the concentration of SDBS and SLA mixture solution by ionic strength Equation (1) and activity coefficient Equation (2). Finally a standard curve of surface tension value versus $\log$ surfactant activity $(\log$ a) will be drawn, $\sigma=m+n \log (a)$ can be obtained. A mathematical model could be built.

$$
I=\frac{1}{2} \sum_{i} C Z_{i}^{2}
$$

I: ionic strength; $\mathrm{C}_{\mathrm{i}}(\mathrm{mol} / \mathrm{L})$ : the concentration of ion; $\mathrm{Z}_{\mathrm{i}}$ : the charge number of ion.

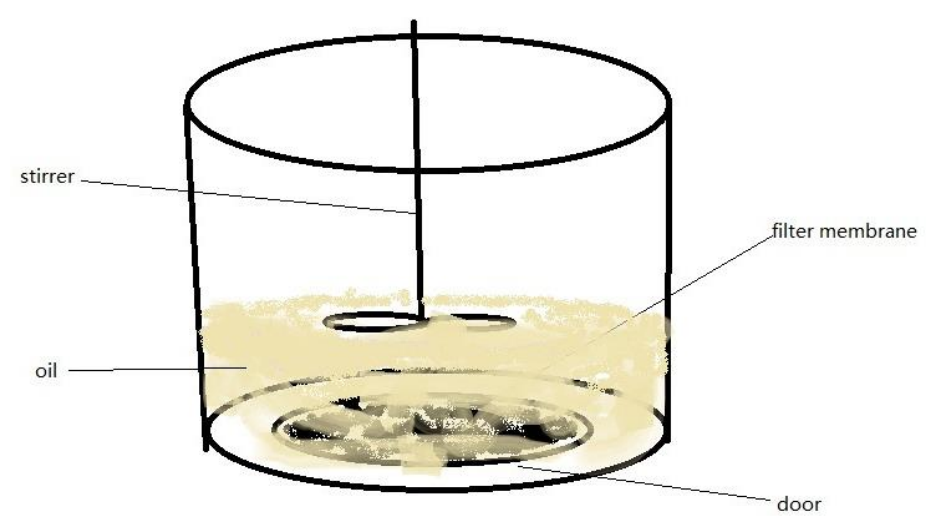

Figure 1. Custom made device. 


$$
\log \gamma_{i}=-Z_{i}^{2} \frac{A \sqrt{I}}{1+\sqrt{I}}
$$

$\gamma_{i}$ : the activity coefficient of ion; A: the coefficient related with solvent and temperature.

$$
\sigma=m+n \log (a)
$$

$\sigma$ : surface tension; a: surfactant activity; $\mathrm{m}, \mathrm{n}$ : coefficient of the equation.

The custom device will be placed inside of a vessel with OSPW which will be maintained at $50^{\circ} \mathrm{C}$. From force tensiometer, the surface tension value of OSPW can be obtained. After the door of custom made device is opened, paraffin oil will be injected into the device (This is the cause for maintaining the temperature at $50^{\circ} \mathrm{C}$ which is above the melting point of paraffin oil), surface tension value will be recorded when the temperature stabilizes. The oil film of paraffin and adsorbed surfactants which are mainly NAs and sulfonates will be removed after the door of the custom device is closed. Filter membrane will be replaced or cleaned.

Afterwards, the clean custom device will be inserted into new OSPW sample again. After the door of the device is opened, time is recorded as zero when paraffin oil is injected into the device. Dynamic surface tension value can be recorded continuously by bubble pressure tensiometer. When dynamic surface tension value becomes stable, the adsorption reaches the equilibrium, and the time is recorded as the adsorption equilibrium time.

Then the custom device will be removed from the vessel and cleaned. OSPW will be replaced also. The oil film will be replaced with diesel and soybean oil sequentially at room temperature. The forward experimental steps will be repeated.

\section{Mathematical Model}

The line for surface tension versus surfactant activity Log value was drawn in Figure $\mathbf{2}$ based on data in Table $\mathbf{1}$. From Figure 2, the equation can be determined as the following.

$$
\sigma=-17.51 \log (a)-42.42
$$

From Equation (4), the equivalent activity can be determined as the following.

$$
a_{e}=10^{-5-\frac{\sigma+42.42}{17.51}}(\mathrm{~mol} / \mathrm{L})
$$

$a_{e}$ : equivalent activity of surfactants.

From Equation (5), the equivalent concentration can be determined as the following.

$$
C_{e}=\frac{10^{-2-\frac{\sigma+42.42}{17.51}}}{\gamma} \times 263(\mathrm{mg} / \mathrm{L})
$$

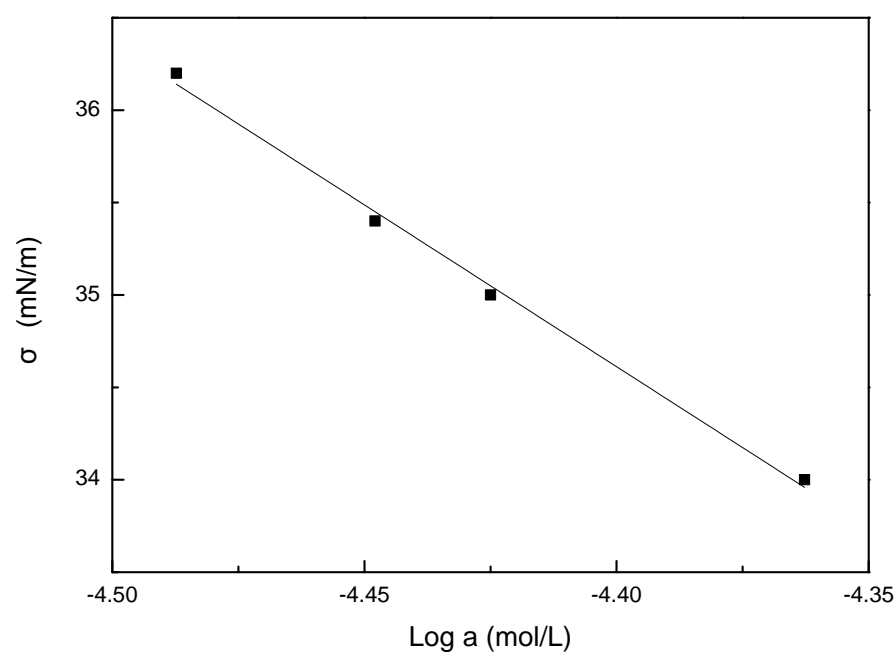

Figure 2. The line for surface tension versus surfactant activity Log value for SDBS and SLA mixture solution at1:1 molar ratio (adapted from [10]). 
Table 1. The change of surface tension $(\sigma)$ with surfactant activity (a) for SDBS and SLA mixture solution at 1:1 molar ratio (taken from [10]).

\begin{tabular}{cccc}
\hline $\log \mathrm{C}(\mathrm{mol} / \mathrm{L})$ & -4.2820 & -4.2426 & -4.2197 \\
$\mathrm{C}\left(10^{-5} \mathrm{~mol} / \mathrm{L}\right)$ & 5.2240 & 5.7200 & 6.0298 \\
$\mathrm{a}\left(10^{-5} \mathrm{~mol} / \mathrm{L}\right)$ & 3.2561 & 3.5653 & 3.7584 \\
$\log \mathrm{a}(\mathrm{mol} / \mathrm{L})$ & -4.4873 & -4.4479 & -4.4250 \\
$\sigma(\mathrm{mN} / \mathrm{m})$ & 36.20 & 35.40 & 35.00 \\
\hline
\end{tabular}

$\mathrm{C}_{\mathrm{e}}$ : equivalent concentration of surfactant; $\gamma$ : activity coefficient of surfactant.

The percentage of surfactant molecules removed can be determined as the following.

$$
\text { Ads } \%=1-10^{(\sigma \mathrm{l}-\sigma 2) / 17.51}
$$

Ads\%: percentage of surfactant molecules removed; $\sigma_{1}, \sigma_{2}$ : surface tension measured at the beginning and the end of the process respectively.

Hence, a mathematical model will be built for determining the equivalent concentration of surfactants in OSPW including NAs based on the surface tension value measured. The percentage of surfactant molecules removed can be calculated also.

\section{Results}

The standard curve of surface tension value versus log surfactant activity (Log a) obtained could be almost the same as the one in the part 3. Thus, the mathematical model could be successfully built and later be tested with different surfactants and mixes of them. It could be expected that paraffin, diesel and soybean oil are all good materials to be used as oil films. The removal efficiency of paraffin might be the highest because the Van der Walls force between hydrophobic tails of surfactants and paraffin oil molecules are the strongest among three of them due to the biggest molecular weight of paraffin. Soybean oil could be the second highest due to the same reason, and diesel could be the least. The equilibrium time of adsorption reaction would be about tens of minutes.

It could be predicted that most of surfactant molecules will move from air-water surface to the oil-water interface until the equilibrium. The fraction of the surfactant adsorbed at the oil-water interface will be almost $90 \%$ when the area ratio of oil-water interface and air-water surface is about 1:5. Hence, the percentage of surfactants removed could be around $90 \%$. Surfactant molecules will continue to move to the oil-water interface after the oil film (with adsorbed NAs) is renewed. This process will promote the migration and further elimination of NAs.

\section{Discussion}

The accuracy of the mathematical model is based on the selection of standard surfactants which are used to create the standard curve. Since there are mainly two types of surfactants in OSPW, and their surface properties would be improved due to synergistic effect. Two types of surfactants, SDBS and SLA, which are mainly used in EOR will be selected as standard surfactants. By Equation (6), the equivalent concentration of surfactants can be determined for comparison. The percentage of surfactants removed can be calculated by Equation (7) to estimate the removal efficiency.

The change of Gibbs free energy $\left(\Delta \mathrm{G}^{\circ}\right)$ reflects the trend of reaction. The negative value of $\Delta \mathrm{G}^{\circ}$ illustrates that the related reaction will occur spontaneously. Since gas molecules are less and smaller than molecules of oil phase, the interaction between gas molecules and surfactant hydrophobic groups is much weaker than that of the oil phase molecules. Hence, $\Delta \mathrm{G}^{\circ}$ of surfactants adsorption at oil (paraffin)-water interface is more negative than that at air-water surface [11]. The detail information is shown in Table 2.

The methylene group $\left(\mathrm{CH}_{2}\right)$ is part of the hydrophobic tail of surfactant molecule, which is alkyl group $\mathrm{CH}_{3}\left(\mathrm{CH}_{2}\right)_{\mathrm{n}-1}$. In Table 2, it shows that $\Delta \mathrm{G}^{\circ}$ value per methylene group at oil (paraffin)-water interface is -3.4 
$\mathrm{KJ} / \mathrm{mol}$, which is lower than that at air-water surface $(-2.5--3.3 \mathrm{KJ} / \mathrm{mol})$. Consequently, $\Delta \mathrm{G}^{\circ}$ per methylene group for surfactants moving from air-water surface to oil(paraffin)-water interface is from -0.1 to $-0.9 \mathrm{KJ} / \mathrm{mol}$. $\Delta \mathrm{G}^{\circ}$ for this adsorption reaction is negative. Thus, this process will occur spontaneously.

For NAs critical micelle concentration (CMC) is over $1 \mathrm{mmol} / \mathrm{L}$ [11] [12], which means more than $300 \mathrm{mg} / \mathrm{L}$. Since the highest value of surfactant concentration in the oil sands tailing water is only $130 \mathrm{mg} / \mathrm{L} \mathrm{[3]}$, it can be believed that Gibbs free energy change per methylene group for surfactant molecules adsorbed at the water surface is close to $-2.5 \mathrm{KJ} / \mathrm{mol}$, while that at the oil-water interface is $-3.4 \mathrm{KJ} / \mathrm{mol}$. Hence, the change of $\Delta \mathrm{G}^{\circ}$ for surfactant molecules moving from the air-water surface to oil-water interface is about $-0.9 \mathrm{KJ} / \mathrm{mol}$. For the average 12-methylene surfactant molecules, that difference is almost $-10.8 \mathrm{KJ} / \mathrm{mol}$. In Figure 3, it is shown that the absolute value of that difference for alkyl methyl sulphoxide, 1-alkyl-3-methylimidazolium chloride and alkyl-trimethyl-ammonium chloride all increase with the number of methylene group. The change of $\Delta \mathrm{G}^{\circ}$ for dodecyl-methyl-sulphoxide and dodecyl-trimethyl-ammonium chloride are close to $-10.5 \mathrm{KJ} / \mathrm{mol}$. That for 1-dodecyl-3-methylimidazolium chloride is close to $-11 \mathrm{KJ} / \mathrm{mol}$. Consequently, that value of $-10.8 \mathrm{KJ} / \mathrm{mol}$ can be used for estimation.

Actually, most of surfactant molecules are adsorbed at the interface when its concentration is lower than CMC. Consequently, the adsorption of surfactants at the oil-water interface competes with that at the air-water surface.

Surfactants (in the solution) $\stackrel{\text { adsorption }}{\longrightarrow}$ surfactants (at the oil-water interface)

$$
\Delta G=-10800 \mathrm{~J} / \mathrm{mol}
$$

From chemical equilibrium equation

$$
\Delta G=-R T L n K e
$$

the equilibrium constant for this process can be determined to be 55.8 ( $\mathrm{T}$ is equal to $323 \mathrm{~K}$ which is above the melting point of Paraffin, $\mathrm{R}$ is equal to $8.314 \mathrm{Jmol}^{-1} \mathrm{~K}^{-1}$ ). The equilibrium constant is equal to the adsorption concentration at oil-water interface divided by that at air-water surface. Hence, the adsorption concentration at oil-water interface is 55.8 times as high as that at air-water surface.

Due to the amount of adsorption depending on the interfacial area, a large area ratio for the oil-water interface and air-water surface is beneficial for increasing the fraction of surfactants adsorbed at the oil-water interface. For the small area of oil sands tailing pond, the area ratio for the oil-water interface and air-water surface is high. Hence, the fraction of surfactants adsorbed at the oil-water interface would be high. Surfactants will be removed much fast. However, that fraction might not be high when an instrument with limited area of adsorption oil film is used in the large area of lakes or ponds. But as long as the oil film is constantly renewed, surfactants can be removed continuously. Consequently, no matter what the area ratio for the oil-water interface and air-water surface is, most of surfactants will be eliminated finally, including NAs.

Using the adsorption property of naphthenic acid at the oil-water interface and removing these harmful substances without forming new pollutants to the environment is a good alternative. Of course, all types of surfactant molecules will be adsorbed at the oil-water interface, including biosurfactants which are produced by microorganisms.

\section{Conclusions}

A mathematical model will be built based on the standard curve, which is used to estimate the surfactant concentration and elimination efficiency. Due to different surfactant adsorption ability at different interfaces, surfactants including NAs can constantly move to oil-water interface, and thus be removed. This process does not add any other substance, so no derivatives will be left in the water. Its expense is much low. This process is easy

Table 2. The change of Gibbs free energy for surfactant adsorption at different interface (taken from [11]).

\begin{tabular}{cc}
\hline Interface & $\Delta \mathrm{G}^{\circ} / \mathrm{CH}_{2}(\mathrm{KJ} / \mathrm{mol})$ \\
\hline Air-Water & $-2.5--3.3$ (saturated) \\
Oil(Paraffin)-Water & -3.4 \\
\hline
\end{tabular}




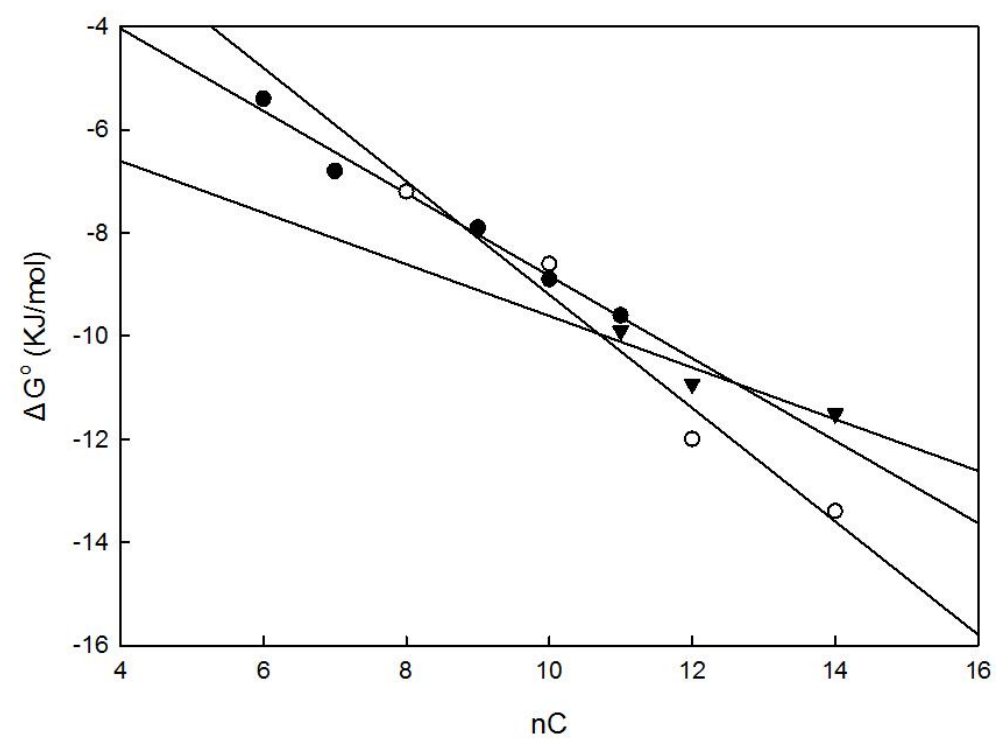

Figure 3. Lines of the change of Gibbs free energy for alkyl-methyl-sulphoxide (•), 1-alkyl-3-methylimidazolium chloride (०) and alkyl-trimethylammonium chloride $(\boldsymbol{\nabla})$ moving from the air-water surface to oil-water interface versus the number of methylene group (adapted from [13]-[15]). nC: the number of methylene group.

to implement and has a low cost in comparison with current methods. It is also easy to operate and the percentage of surfactants removed could be high. The time of surfactants moving measured by the bubble pressure tensiometer, which is the time required to reach adsorption equilibrium, can be determined to be about tens of minutes. That makes it possible to use automatic instrument for removing NAs in the future, whose updated time for the oil film need to be set up depending on the adsorption equilibrium time. The further work is continuing.

\section{References}

[1] Schramm, L.L., Smith, R.G. and Stone, J.A. (1984) Interfacial Chemistry of the Hot Water Process for Recovering Bitumen from the Athabasca oil Sands. Abstracts of Papers of the American Chemical Society, 29, 209-216.

[2] Schramm, L.L. and Smith, R.G. (1985) The Influence of Natural Surfactants on Interfacial Charges in the Hot-Water Process for Recovering Bitumen from the Athabasca Oil Sands. Colloids and Surfaces, 14, 61-85. http://dx.doi.org/10.1016/0166-6622(85)80042-1

[3] Grewer, D.M., Young, R.F., Whittal, R.M. and Fedorak, P.M. (2010) Naphthenic Acids and Other Acid-Extractables in Water Samples from Alberta: What Is Being Measured? Science of the Total Environment, 408, 5997-6010. http://dx.doi.org/10.1016/j.scitotenv.2010.08.013

[4] Headley, J.V. and McMartin, D.W. (2004) A Review of the Occurrence and Fate of Naphthenic Acids in Aquatic Environments. Journal of Environmental Science and Health Part A-Toxic/Hazardous Substances \& Environmental Engineering, 39, 1989-2010. http://dx.doi.org/10.1081/ESE-120039370

[5] Rocknold, W. (1955) Toxicity of Naphthenic Acids and Their Metal Salts. AMA Arch Ind Health, 12, 477-482.

[6] Kindzierski, W., Jin, J. and El-Din, M.G. (2012) Review of Health Effects of Naphthenic Acids: Data Gaps and Implications for Understanding Human Health Risk. Oil Sands Research and Information Network, University of Alberta, School of Energy and the Environment, 1-43.

[7] Scott, A.C., Mackinnon, M.D. and Fedorak, P.M. (2005) Naphthenic Acids in Athabasca Oil Sands Tailings Waters Are Less Biodegradable than Commercial Naphthenic Acids. Environmental Science \& Technology, 39, 8388-8394. http://dx.doi.org/10.1021/es051003k

[8] Hwang, G., Dong, T., Islam, M.S., Sheng, Z., Pérez-Estrada, L.A., Liu, Y. and El-Din, M.G. (2013) The Impacts of Ozonation on Oil Sands Process-Affected Water Biodegradability and Biofilm Formation Characteristics in Bioreactors. Bioresource Technology, 130, 269-277. http://dx.doi.org/10.1016/j.biortech.2012.12.005

[9] Li, H.J., Cao, Y.M., Yang, L.S. and Yuan, Q. (2005) Oil-Water Separation Performance of Anti-Fouling $\alpha$-Cellulose Hollow Fiber Ultrafiltration Membrane. Chemical Journal of Chinese Universities, 26, 1890-1895. 
[10] Yang, P.H., Weng, R., Luo, Y.S., Sun, Z.B., Zhang, Y.F. and Li, C.Y. (2004) Micellar Properties of Mixed AnionicNonionic Surfactants. Petroleum Exploration and Development, 31, 129-132.

[11] Zhao, G.X. and Zhu, S.Y. (2003) Principles of Surfactant Action. China Light Industry Press, 1-764.

[12] Yu, K.P., Yu, Y.F. and Yang, G.C. (2013) Designing and Mechanism of Dephosphorization Collector Molecular of Iron Ore Reverse Flotation. The Chinese Journal of Nonferrous Metals, 23, 585-591.

[13] Tadros, T.F. (2005) Applied Surfactants: Principles and Applications. Wiley-VCH Verlag GmbH \& Co. KGaA, Weinheim, 1-634.

[14] Bai, G., Lopes, A. and Bastos, M. (2008) Thermodynamics of Micellization of Alkylimidazolium Surfactants in Aqueous Solution. Journal of Chemical Thermodynamics, 40, 1509-1516. http://dx.doi.org/10.1016/j.jct.2008.05.016

[15] Perger, T.M. and Bester-Rogac, M. (2007) Thermodynamics of Micelle Formation of Alkyltrimethylammonium Chlorides from High Performance Electric Conductivity Measurements. Journal of Colloid and Interface Science, 313, 288-295. http://dx.doi.org/10.1016/j.jcis.2007.04.043 